\title{
The need for monitoring the actual nitric oxide concentration in tumors
}

\author{
Adam Heller \\ Received: 2 January 2009 / Accepted: 2 April 2009/Published online: 3 June 2009 \\ (C) The Author(s) 2009. This article is published with open access at Springerlink.com
}

\begin{abstract}
The significance of the role of nitric oxide (NO) in cancer is evident from 1,100 publications on the subject; its triggering of apoptosis at high concentrations is documented in 300 publications. While aspects of the rate of generation of NO in tumors have been extensively studied, the rate of its removal from tumors has not been considered, even though it is the difference between the two rates that determines the all important steady-state NO concentration, and thus the likelihood of apoptosistriggering. The rate of transport of NO scales with its concentration gradient at the interface between a neoplasm and the phase to which it diffuses, which can be air, fat, or blood. Diffusional loss of NO to air would explain the initial two-dimensionality of neoplasms of the skin and lung. The greater solubility of NO in lipids than in aqueous phases should cause its extraction by nearby fat, and would account for the positive correlation between obesity and the incidence of some cancers, such as cancers of the breast. And the rapid consumption of $\mathrm{NO}$ by red blood cells implies depletion of excess NO in tumors after they are vascularized: angiogenesis should blunt any apoptosistriggering NO attack of the immune system. Thus, cancer research and the practice of oncology may benefit of intumor monitoring of the actual NO concentration. Miniature NO monitoring electrodes, that might serve the purpose, are reviewed.
\end{abstract}

Keywords Cancer . Nitric oxide depletion $\cdot$ Apoptosis $\cdot$ Air interface $\cdot$ Body fat $\cdot$ Angiogenesis $\cdot$ Tumor shape

\footnotetext{
A. Heller $(\bowtie)$

Department of Chemical Engineering, University of Texas, Austin, TX 78712, USA

e-mail: heller@che.utexas.edu
}

\section{Introduction}

One thousand and one hundred articles have been published on the role of nitric oxide (NO) in cancer. The immune system recognizes neoplasms and attacks, or attempts to attack, these by increasing the NO concentration. NO is the smallest, fastest-diffusing, water- and lipid-soluble, membrane-permeating molecule in the immune system's arsenal. To raise the local NO concentration in the neoplasm, the immune system increases the local iNOS activity, for example by local recruiting and stimulation of macrophages. Three hundred publications, 40 on cancer, show that at high concentrations NO triggers apoptosis. The apoptosis-triggering $\mathrm{NO}$ concentrations are $>1 \mu \mathrm{M}$, about a thousand-fold higher than the vasodilation-causing concentrations. Nevertheless, the actual tumor NO concentrations are rarely monitored. While most of the 1,100 publications consider an aspect of the generation of NO, few, if any, consider the equally important removal of nitric oxide from tumors. The most often-measured NO-generation-related parameters are the expression of inducible nitric oxide synthase, iNOS, and the expression of endothelial nitric oxide synthase, eNOS. Both enzymes catalyze Reaction 1. Other frequently measured NO-generation related parameters

Arginine $+\mathrm{O}_{2} \rightarrow$ citrulline $+\mathrm{NO}$

are the expression of iNOS at the mRNA level; the expressions of cytokines inducing or inhibiting iNOS expression; the actual iNOS activity in the tumor; concentrations of $\mathrm{NO}_{2}{ }^{-}$and $\mathrm{NO}_{3}{ }^{-}$, both products of $\mathrm{NO} ; \mathrm{NO}_{2}{ }^{-}$-concentration dependent diazotizations, whereby colored or fluorescent products are formed; and, in a few publications, the concentration of arginine, the 
precursor of NO (Reaction 1). In some neoplasms the generation of excess NO is impaired [1].

The all important steady-state NO concentration in tumors depends equally on both the rate of $\mathrm{NO}$ generation and on the rate of NO elimination. The latter has not been sufficiently considered. In absence of actual tumor NO concentration measurements, and in absence of estimates of $\mathrm{NO}$ elimination rates in neoplasms, there is no information on the steady-state $\mathrm{NO}$ concentration, even though it may determine the relative rates of cell proliferation and apoptosis.

NO dissolves and diffuses in both lipids and aqueous solutions. It permeates through cell membranes [2], walls of blood-vessels, and skin. Consequently, it is eliminated by

1. out-diffusion from air-contacting neoplasms to ambient air;

2. extraction by, and oxidation in, proximal fat (Reaction 2);

3. diffusion to, and reactions in, erythrocytes of the circulating blood (Reactions 3-5).

In addition, NO is effectively scavenged by the inflammatory superoxide radical anion $\mathrm{O}_{2}^{-}$[3].

\section{High incidence and flatness of neoplasms at the air-interface}

The rate of diffusion of NO to ambient air lowers the iNOSproduced excess of $\mathrm{NO}$ in neoplasms of the skin. Its transport to the 12-20 times per minute inhaled/exhaled air of the lungs also suppresses its concentration in neoplasms of the lung. Possibly because neoplasms at air interfaces lose their excess NO concentration, they survive the immune system's NO attack making the development of cancers of the skin and the lung more likely than the development of other cancers. Of the 2.1 million new (2008) cancers in the USA, more than $1,062,000$ are projected to be cancers of the skin and 215,000 of the lung [4]. While the mutagenic-carcinogenic effect of UV-B exposure of the skin and the effects of airborne carcinogens on the lung are not questioned, the high incidence of air-contacting cancers suggests that loss of tumor NO to air should also be considered among the causes of the high incidence of skin and lung cancers.

The suggestion that $\mathrm{NO}$ transport from a neoplasm to air blunts the NO attack of the immune system is supported by the shapes and loci of the early skin and lung cancers. If outdiffusion of $\mathrm{NO}$ to ambient air would not be of essence, i.e. if the likelihood of apoptosis of cells would not increase with their distance from the air-interface, then the proliferation of cancercells would be isotropic and tumors would grow to be about spherical. If, however, those cells that are nearer to air-interface would survive the NO attack, while those removed from the airinterface would undergo apoptosis, then the nascent neoplasms would be flat, nearly two-dimensional. Their estimated thickness would be a small multiple of the NO diffusion length, estimated at $0.1-1 \mathrm{~mm}$ for tissues other than blood, i.e. for not-yet-vascularized neoplasms. Indeed, most of the nascent cancers of the skin are at the air-interface: skin cancers begin at the dermal-epidermal junction, and invade only later the deeper fatty dermis. Skin cancers starting at the dermal-epidermal junction include basal cell carcinomas, squamous cell carcinomas, and melanomas. Many of the early lung cancers are also confined to the lining at the air-interface. Small cell lung carcinomas arise mostly in the mucosal layer of one of the large bronchi, over which the air-flow is particularly rapid. Many lung cancers start in cells at the mucosa of a bronchus, the cells undergoing squamous metaplasia, i.e. morphing into squamous cells. For this reason, oncological pathologists examining lung cancers always look for evidence of in situ carcinoma in the bronchial mucosa. Fast air-flow makes the boundary layer thin (boundary layer is the engineering term for the interfacial layer across which the $\mathrm{NO}$ concentration drops). As a consequence of the thin boundary layer, the rate of the out-diffusion of $\mathrm{NO}$, which scales with the NO concentration gradient, is rapid. In peripheral, non-bronchial lung adenocarcinomas the growth also starts in the mucosal lining at the air-interface.

\section{Body fat and cancer}

In the absence of an NO-oxidation catalyst, the rate of the ter-molecular reaction whereby $\mathrm{NO}$ is oxidized by $\mathrm{O}_{2}$ to $\mathrm{NO}_{2}$ (Reaction 2) scales with the square of the $\mathrm{NO}$ concentration and with the cube of the dissolved gas concentration. The solubilities of $\mathrm{NO}$ and $\mathrm{O}_{2}$ in lipids exceed about threefold their solubilities in $\mathrm{pH} 7.4$ aqueous saline solutions [5]. This greater lipid solubility of NO

$2 \mathrm{NO}+\mathrm{O}_{2} \rightarrow 2 \mathrm{NO}_{2}$

should lead to its extraction from a neoplasm by proximal adipose tissue. Because of the threefold higher $\mathrm{NO}$ and $\mathrm{O}_{2}$ concentrations in fat, the rate of the NO-eliminating Reaction 2 is at least tenfold faster than it is in a nonfatty tissue. As the breast is constituted mostly of fatty tissue, breast carcinomas are often proximal to, or within, fat. That obesity and cancer are positively correlated is documented in more than 530 publications, about 140 on cancers of the breast.

\section{Angiogenesis and the virulence of cancers}

Neoplasms turn into aggressive cancers when they are vascularized. The rate of loss of NO to circulating blood dwarfs the rates of its loss to air or to fat. Reactions 3-5 dominate the elimination of NO by blood. These reactions are fast and drastically limit the blood NO concentration [6]. Cancers in which Reactions 3-5 may affect the cellular 
NO concentrations already at the nascent stage include leukemia and lymphomas. NO elimination by blood is, however, most important in mature, vascularized tumors. The lifetime work of the late Judah Folkman and of his associates established through the past 40 years the relative dormancy of cancers until their vascularization. They showed that angiogenesis, leading to vascularization, makes the tumors virulent $[7,8]$.

The erythrocyte volume fraction (hematocrit) in blood is near 0.45 . Because oxyhemoglobin $\left(\mathrm{HbFe}(\mathrm{II}) \mathrm{O}_{2}\right)$ constitutes $35 \%$ of the wet-weight of the erythrocytes, blood contains $16 \mathrm{wt} \% \mathrm{HbFe}(\mathrm{II}) \mathrm{O}_{2}$. The molecular mass of $\mathrm{HbFe}$ (II) $\mathrm{O}_{2}$ is 64,000 and each molecule comprises two $\beta$ chains, each with a cys93. Thus, the concentration of the NO-reactive cys 93 in blood is as high as $5 \mathrm{mM}$. The NO concentration gradient near a tumor blood vessel is so large that it can be said that the circulating blood sucks out the excess NO of the immune system's attack. Now the rate of cell proliferation is no longer diminished by high NOconcentration-triggered apoptosis.

$$
\begin{aligned}
& \mathrm{HbFe}(\mathrm{II}) \mathrm{O}_{2} \text { cys } 93-\mathrm{SH}+\mathrm{NO} \\
& \leftrightarrow \mathrm{HbFe}(\mathrm{II}) \mathrm{O}_{2} \text { cys93 }-\mathrm{SNO}+\mathrm{H}^{+}+\mathrm{e}^{-}
\end{aligned}
$$

Glutathione $-\mathrm{SH}+\mathrm{NO} \leftrightarrow$ Glutathione $-\mathrm{SNO}+\mathrm{H}^{+}+\mathrm{e}^{-}$

$\mathrm{HbFe}(\mathrm{II}) \mathrm{O}_{2}+\mathrm{NO} \rightarrow$ metHbFe$(\mathrm{III})+\mathrm{NO}_{3}^{-}$

\section{Implantable NO-monitoring electrodes}

Although implantable electrodes with a wide dynamic range, suitable for monitoring NO in living tumors, are not yet in hand, there are electrodes that could be modified for this purpose. Tadeusz Malinski pioneered tissue-implanted amperometric NO sensors, based on porphyrin-catalyzed electrooxidation of $\mathrm{NO}$ [9-11]. He designed, for example, 1-20 $\mu \mathrm{m}$ diameter sensors, detecting $10^{-9} \mathrm{M} \mathrm{NO}$, with a $0.1-$ $10 \mathrm{~ms}$ response time, protected by an i.v. catheter or a SwanGanz catheter. He applied such sensors in the monitoring of NO in the cardiovascular system [12, 13]. Subsequent NOmonitoring electrodes were implanted in organs of animals, particularly in rats, including their retina and brain [14-16]. The porphyrinic and phthalocyanine-based catalysts were improved through derivatization and screening of large libraries [17, 18] and nickel-containing porphyrinic and phthalocyanine-based electrocatalysts are now preferred for in vivo applications [19-24]. Indeed, the latter have already been implanted in a tumor [25]. Membranes improved the specificity of the electrodes in vivo. [26, 27]. High spatial resolution was achieved [28] and the electrodes' diameter has been reduced to nanometers with the NO detection limit lowered to $0.3 \mathrm{nM}$. [29, 30]. Platinized platinum [31] and platinum-iridium anodes have also been introduced [32] and microchip-based, membrane-coated NO microsensors have been described [23]. Of the recently reported electrochemical-amperometric NO sensors, those of Shin et al. and Thangavel et al. might develop into particularly useful tumor NO-monitoring systems [33, 34]. A current review summarizes the principles and status of NOmonitoring electrodes [35].

\section{Conclusion}

The considerations presented suggest that cancer research and oncological practice would benefit from in-tumor monitoring of the actual concentration of NO. An increase in the $\mathrm{NO}$ concentration in a tumor to $>1 \mu \mathrm{M}$ would indicate effective treatment and would be a favorable prognostic indicator.

Acknowledgement Support of the Welch Foundation (Grant 1131) is gratefully acknowledged.

Open Access This article is distributed under the terms of the Creative Commons Attribution Noncommercial License which permits any noncommercial use, distribution, and reproduction in any medium, provided the original author(s) and source are credited.

\section{References}

1. Heller A (2008) Apoptosis-inducing high NO concentrations are not sustained either in nascent or in developed cancers. Chem Med Chem 3:1493-1499

2. Moller MN, Lancaster JR Jr, Denicola A (2008) The interaction of reactive oxygen and nitrogen species with membranes. Curr Top Membr 61:23-42

3. Beckman JS, Koppenol WH (1996) Nitric oxide, superoxide, and peroxynitrite: the good, the bad, and the ugly. Am J Physiol 271: C1424-C1437

4. National-Cancer-Institute. Common Cancers Vol. 2008 (ed. http:// www.cancer.gov/cancertopics/commoncancers) (National Cancer Institute, 2008).

5. Moeller M et al (2005) Direct measurement of nitric oxide and oxygen partitioning into liposomes and low density lipoprotein. $\mathrm{J}$ Biol Chem 280:8850-8854

6. Liu X, Yan Q, Baskerville KL, Zweier JL (2007) Estimation of nitric oxide concentration in blood for different rates of generation: evidence that intravascular nitric oxide levels are too low to exert physiological effects. J Biol Chem 282:8831-8836

7. Folkman J, Heymach J, Kalluri R (2006) Tumor angiogenesis. Cancer Med 7:157-191

8. Naumov GN, Akslen LA, Folkman J (2006) Role of angiogenesis in human tumor dormancy. Animal models of the angiogenic switch. Cell Cycle 5:1779-1787 
9. Vallance P et al (1995) Direct measurement of nitric oxide in human beings. Lancet 346:153-154

10. Gerova $\mathrm{M}$ et al (1996) Nitric oxide in the periendothelial area of femoral vein of the dog assessed in vivo by a porphyrinic sensor. Physiol Res (Prague) 45:285-289

11. Malinski T, Mesaros S, Tomboulian P (1996) Nitric oxide measurement using electrochemical methods. Methods Enzymol 268:58-69

12. Malinski T, Mesaros S, Patton SR, Mesarosova A (1996) Direct measurement of nitric oxide in the cardiovascular system. Physiol Res (Prague) 45:279-284

13. Malinski T (2000) Porphyrin-based electrochemical sensors. Porphyrin Handb 6:231-256

14. Groppe M, Thanos S, Schuhmann W, Heiduschka P (2003) Measurement of nitric oxide production by the lesioned rat retina with a sensitive nitric oxide electrode. Anal Bioanal Chem 376:797-807

15. Mas M, Escrig A, Gonzalez-Mora JL (2002) In vivo electrochemical measurement of nitric oxide in corpus cavernosum penis. J Neurosci Methods 119:143-150

16. Barbosa RM et al (2008) In vivo real-time measurement of nitric oxide in anesthetized rat brain. Methods Enzymol 441:351-367

17. Diab $N$ et al (2003) Pyrrole functionalised metalloporphyrins as electrocatalysts for the oxidation of nitric oxide. Talanta 61:43-51

18. Ryabova V, Schulte A, Erichsen T, Schuhmann W (2005) Robotic sequential analysis of a library of metalloporphyrins as electrocatalysts for voltammetric nitric oxide sensors. Analyst (Cambridge, United Kingdom) 130:1245-1252

19. Villeneuve N, Bedioui F, Voituriez K, Avaro S, Vilaine JP (1998) Electrochemical detection of nitric oxide production in perfused pig coronary artery: comparison of the performances of two electrochemical sensors. J Pharmacol Toxicol Methods 40:95-100

20. Pontie M, Gobin C, Pauporte T, Bedioui F, Devynck J (2000) Electrochemical nitric oxide microsensors: sensitivity and selectivity characterisation. Anal Chim Acta 411:175-185

21. Pailleret A et al (2003) In situ formation and scanning electrochemical microscopy assisted positioning of NO-sensors above human umbilical vein endothelial cells for the detection of nitric oxide release. Electrochem Commun 5:847-852

22. Chang S-C et al (2005) An electrochemical sensor array system for the direct, simultaneous in vitro monitoring of nitric oxide and superoxide production by cultured cells. Biosens Bioelectron 21:917-922

23. Isik S et al (2005) Cell-compatible array of three-dimensional tip electrodes for the detection of nitric oxide release. Biosens Bioelectron 20:1566-1572

24. Oni J, Diab N, Reiter S, Schuhmann W (2005) Metallophthalocyanine-modified glassy carbon electrodes: effects of film formation conditions on electrocatalytic activity towards the oxidation of nitric oxide. Sens Actuators, B B105:208-213

25. Griveau $S$ et al (2007) In vivo electrochemical detection of nitric oxide in tumor-bearing mice. Anal Chem 79:1030-1033

26. Friedemann MN, Robinson SW, Gerhardt GA (1996) oPhenylenediamine-modified carbon fiber electrodes for the detection of nitric oxide. Anal Chem 68:2621-2628

27. Zhang X, Cardosa L, Broderick M, Fein H, Lin J (2000) An integrated nitric oxide sensor based on carbon fiber coated with selective membranes. Electroanalysis 12:1113-1117

28. Kitamura $\mathrm{Y}$ et al (2000) Microcoaxial electrode for in vivo nitric oxide measurement. Anal Chem 72:2957-2962

29. Zhang $X$ et al (2002) Nanometer size electrode for nitric oxide and S-nitrosothiols measurement. Electrochem Commun 4:11-16

30. Zhang X, Lin J, Cardoso L, Broderick M, Darley-Usmar V (2002) A novel microchip nitric oxide sensor with sub-nM detection limit. Electroanalysis 14:697-703

31. Lee Y, Oh BK, Meyerhoff ME (2004) Improved planar amperometric nitric oxide sensor based on platinized platinum anode. 1 . Experimental results and theory when applied for monitoring NO release from diazeniumdiolate-doped polymeric films. Anal Chem 76:536-544

32. Dickson A et al (2004) Construction and characterization of a new flexible and nonbreakable nitric oxide microsensor. Electroanalysis 16:640-643

33. Shin JH, Privett BJ, Kita JM, Wightman RM, Schoenfisch MH (2008) Fluorinated xerogel-derived microelectrodes for amperometric nitric oxide sensing. Anal Chem (Washington, DC, United States) 80:6850-6859

34. Thangavel S, Ramaraj R (2008) Polymer membrane stabilized gold nanostructures modified electrode and its application in nitric oxide detection. J Phys Chem C 112:19825-19830

35. Davies IR, Zheng X (2008) Nitric oxide selective electrodes. Methods Enzymol 436:63-95 